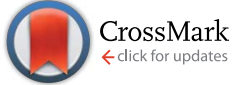

Cite this: RSC Adv., 2015, 5, 86997
Received 30th July 2015

Accepted 7th October 2015

DOI: $10.1039 / c 5 r a 15201 a$

www.rsc.org/advances

\section{Influence of water on the retention of methyl tertiary-butyl ether by high silica ZSM-5 and Y zeolites: a multidisciplinary study on the adsorption from liquid and gas phase $\uparrow$}

\begin{abstract}
A. Martucci, ${ }^{a}$ I. Braschi, ${ }^{\star b}$ C. Bisio, ${ }^{\text {C E. Sarti, }}{ }^{d}$ E. Rodeghero, ${ }^{a}$ R. Bagatin ${ }^{e}$ and L. Pasti ${ }^{\star d}$
Ambient temperature adsorption isotherms have been determined for methyl tert-butyl ether (MTBE) in aqueous solutions on high silica ZSM-5 and $Y$ zeolites which differ from each other in framework topology and pore window apertures. The comparison of their adsorption properties was performed to evaluate the importance of the competitive interference of water with pore size. The adsorption Henry's constants for MTBE decrease with an increase in the zeolite pore size, indicating that confinement of the adsorbate in the zeolite pores is a driving force for adsorption. On the contrary, the saturation capacity increases with an increase in the adsorbent pore size (i.e. about 95 and $250 \mathrm{mg} \mathrm{g}^{-1}$ for ZSM-5 and Y, respectively). These data were confirmed from Rietveld refinement, that clearly revealed the incorporation of about 8 and 32 MTBE molecules per ZSM-5 and Y unit cell respectively. X-ray diffraction and IR spectroscopy indicate that significant clustering of the guest molecules (i.e. water and MTBE) occurs in the two investigated zeolites during adsorption from both the liquid and gas phase. The clusters originate from hydrogen bonding between MTBE and water molecules and their interaction with zeolite lead to framework flexibility for both zeolites. However, the framework deformation in $Y$ is more evident than in ZSM-5 and occurs with a change of the real symmetry. These findings could have an impact on the adsorption, separation and catalytic use of zeolites for oxygenate compounds.
\end{abstract}

\section{Introduction}

Methyl tert-butyl ether (MTBE, $\mathrm{C}_{5} \mathrm{H}_{12} \mathrm{O}$ ) is an important oxygenated compound used as a gasoline additive to increase octane ratings and to improve combustion, thus reducing the emissions of carbon monoxide and hydrocarbons. ${ }^{1}$ This fuel additive is of particular concern in water pollution, ${ }^{2,3}$ due to its high aqueous solubility and high vapour pressure (about 50 $\mathrm{g} \mathrm{L}^{-1}$ and $245 \mathrm{mmHg}$ at $25{ }^{\circ} \mathrm{C}$, respectively $\left.{ }^{4,5}\right)$. MTBE is toxic and is a potential human carcinogen, ${ }^{2}$ moreover it is not readily biodegradable in the natural environment. The U.S.

${ }^{a}$ Department of Physics and Earth Sciences, University of Ferrara, Via G. Saragat 1, I-44123 Ferrara, FE, Italy

${ }^{b}$ Department of Agricultural Sciences, University of Bologna, Viale G. Fanin 44, I-40127 Bologna, BO, Italy

'Department of Sciences and Technological Innovation, University of Eastern Piedmont A. Avogadro, Viale T. Michel 11, I-15121 Alessandria, AL, Italy

${ }^{d}$ Department of Chemistry and Pharmaceutical Sciences, University of Ferrara, Via L. Borsari 46, I-44123 Ferrara, FE, Italy. E-mail: l.pasti@unife.it

${ }^{e}$ Research Center for Non-Conventional Energy - Istituto Eni Donegani Environmental Technologies, via Maritano, 26, San Donato Milanese, MI, I-20097, Italy

$\dagger$ Electronic supplementary information (ESI) available: Pattern diffraction patterns of bare and MTBE loaded zeolites (ZSM-5 and Y). Framework and extra-framework atomic coordinates, and temperature factors are provided (Table S1 and 2 ESI). See DOI: 10.1039/c5ra15201a
Environmental Protection Agency (EPA) has placed MTBE on the drinking water contaminant candidate list for future and has estimated that its levels based on organoleptic effects should not exceed $20 \mu \mathrm{g} \mathrm{L}^{-1}$ in terms of odour and $40 \mu \mathrm{g} \mathrm{L}^{-1}$ in terms of taste. ${ }^{6}$ For these reasons different remediation technologies to reduce MTBE in the environment have been developed. In particular, those based on adsorption of MTBE on solid adsorbent seem to be particularly adequate, since it has been shown that oxidation based remediation can lead to the formation of by-products and background water-related oxidation by-products. ${ }^{7,8}$ Many studies have been conducted to highlight the ability of hydrophobic/organophilic zeolites to selectively extract organic compounds from water ${ }^{9-12}$ but only a few of them have been addressed the effect of water, either in liquid or in vapour phase, on their adsorption (e.g. see ref. 9 and 10). In this field, the works of Milestone and Bibby, ${ }^{9}$ Grose and Flanigen, ${ }^{10}$ and Anderson $^{13}$ were pioneeristic for the introduction of hydrophobic zeolite as adsorbent materials for organic contaminants from water. ${ }^{\mathbf{1 4 - 1 6}}$ In particular in ref. 12 and 13 it has been demonstrated that zeolite materials were more efficient that activate carbon for MTBE removal, and zeolite beta and mordenite exhibited good properties for MTBE adsorption. ${ }^{12,13,16,17}$ One of the main advantage of beta and mordenite zeolites over other adsorbent materials was that no competition 
among the organic matter, commonly dispersed in natural water, and MTBE molecules was observed. ${ }^{12,13}$ In addition, Arletti ${ }^{17}$ highlighted the presence of MTBE in zeolite microporosities by structure refinement performed using the Rietveld method. Among high silica (HS) zeolites, mordenite has been shown to be the best MTBE adsorbent also for gas phase systems. $^{16}$

Recent studies show that others HS zeolites also exhibit considerably large MTBE adsorption uptakes. ${ }^{18}$ The adsorption of MTBE has been also deeply investigated by Rossner and Knappe. ${ }^{14}$ In these studies, short bed adsorbent tests were carried out on both ultrapure and river water, to obtain parameters describing MTBE adsorption equilibria and kinetics. It has been found that, among the studied adsorbents, silicalite was the most cost-competitive adsorbent when considering both life time and usage rate of the adsorbent materials. Most of these studies were devoted to the optimal selection of an efficient adsorbent material based on the comparison of the MTBE uptake from aqueous solutions. However, criteria based solely on macroscopic observations are often not exhaustive for choosing the most efficient sorbent materials, and to gain a full understanding of the different behaviours of these materials. On the other hand, physicists specializing in surface science tend to favour adsorption directly from the gas phase. ${ }^{19}$ This is partly due to the need to simplify the system by avoiding the interference of solvent in modelling and theoretical interpretation. ${ }^{20}$ The results obtained in gas phase systems can be significantly different from those obtained for aqueous solutions, either to clearly evidence a particular adsorption mode, or to mimic what happens when the water activity is decreased by drying. However, it must be kept in mind that when the question has been studied, the presence of water did indeed interfere strongly with organic compounds adsorption modes. ${ }^{21-23}$ In fact, adsorption from aqueous solutions depends not only on the dimension of the pore systems, but also on the interactions among zeolite framework, the adsorbate and water molecules, as recently reported for the adsorption of dichloroethane (DCE) on mordenite, ${ }^{24} \mathrm{ZSM}-5$, and Y zeolites. ${ }^{25}$ Water molecules inside the porous framework lead to a multicomponent system instead of a single component adsorption mechanism and interact with DCE through hydrogen bonding. Interaction between sorbed molecules has also been reported by Krishna and van Baten $^{21}$ in the adsorption of water-alcohol mixtures on zeolites and by Bai et al. ${ }^{20}$ for polyols-zeolite systems. The adsorption from organic-water mixtures markedly differs from that of their pure components and the differences have been ascribed to $\mathrm{H}$-bonding between the adsorbates and zeolite framework. Since MTBE can interact with water through $\mathrm{H}$ bonding as well, in the present study the adsorption of the binary MTBE-water system onto two different HS zeolite materials (i.e. ZSM-5 and Y) was studied in a broad range of conditions.

One of the main target of the present work is in fact to investigate whether the results obtained for chlorinated compounds and alcohols can be generalized to organic compound containing electronegative heteroatoms.

The two selected adsorbents were commercial ZSM-5 and Y zeolites: the possibility to find them on the market was considered a strong decision point for their selection. They differ from each other in structure and in the opening windows of the framework, and the comparison of their adsorption properties was performed to evaluate the importance of the competitive interference of water with pore size. ZSM-5 (MFItype framework topology ${ }^{26}$ ) is a medium pore material whose framework is characterized by four symmetrically independent 10-membered rings (MR) of tetrahedra (in the $P 2_{1} / n$ or $P 2_{1} 2_{1} 2_{1}$ symmetries). Two of these delimit the sinusoidal channel (ZZ) (sinusoidal ring A and sinusoidal ring B, defined in Fig. 1A) and the other two confine the straight channel (SC) (SC ring A and SC ring B, Fig. 1A). The zeolite $\mathrm{Y}$ (FAU-type framework topology ${ }^{26}$ ) is a large pore material with large cavities (referred to as "supercages"), joined to four others via 12MR (see Fig. 1B).

The two selected materials are characterized by a similar silica/alumina $\left(\mathrm{SiO}_{2} / \mathrm{Al}_{2} \mathrm{O}_{3}\right)$ ratio (SAR), however, since the adsorption could be influenced by both the polar (defect density) and nonpolar domains of the framework, ${ }^{27}$ the adsorption of MTBE from both batch aqueous solution and gas phase in the presence of water was studied and the interactions with the framework investigated.

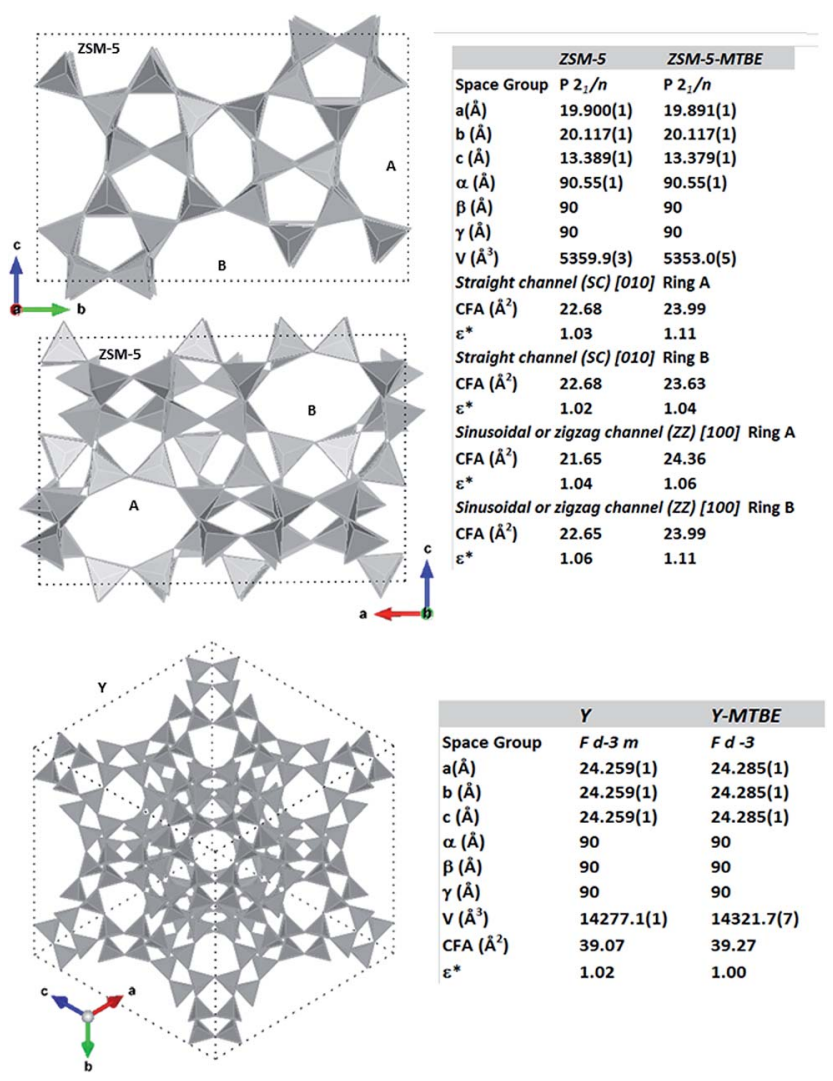

Fig. 1 Unit cell parameters, Crystallographic Free Area (CFA, sensu Baerlocher ${ }^{26}$ ) and channel ellipticity $\left(\varepsilon^{*}\right)$ for ZSM-5 and $Y$ before and after MTBE adsorption. $\varepsilon^{*}=$ ratio between the longest and the shortest pore dimensions. In the picture the $\mathrm{T}$ atom of the $\mathrm{TO}_{4}$ tetrahedron is located at each of the corners, and the oxygen atoms (not shown to aid clarity) are located towards the mid-points of the lines joining each T atom. 


\section{Experimental}

\subsection{Materials and methods}

Materials. MTBE (purity 99.8\%) and sodium chloride (purity 98\%) were obtained from Sigma-Aldrich (Steinheim, Germany). The as-synthesized Y zeolite powder (code HSZ$390 \mathrm{HUA}$ ) with a $200 \mathrm{SiO}_{2} / \mathrm{Al}_{2} \mathrm{O}_{3}$ ratio and a surface area of $750 \mathrm{~m}^{2} \mathrm{~g}^{-1}$, was purchased in its protonated form from Tosoh Corporation (Japan). The $\mathrm{Na}_{2} \mathrm{O}$ content was lower than $0.1 \%$ w/w. ZSM-5 was purchased by Zeolyst International (code $\mathrm{CBV} 28014$ ) in ammonium form with a $280 \mathrm{SiO}_{2} / \mathrm{Al}_{2} \mathrm{O}_{3}$ ratio. The $\mathrm{Na}_{2} \mathrm{O}$ content was lower than $0.05 \% \mathrm{w} / \mathrm{w}$. The surface area is $400 \mathrm{~m}^{2} \mathrm{~g}^{-1}$.

Gas chromatography. The MTBE concentration in aqueous solutions was determined using a gas chromatography-mass spectrometry (GC-MS). Solid phase micro-extraction (SPME) in headspace (HS) mode was used to extract MTBE from aqueous samples. A volume of $10 \mathrm{~mL}$ of aqueous solution in $25 \mathrm{~mL}$ glass flasks was sealed with Teflon ${ }^{\circledR}$ screw caps. $2 \mathrm{~mL}$ of a $300 \mathrm{~g} \mathrm{~L}^{-1} \mathrm{NaCl}$ solution were added to the sample. Samples were immersed in a thermostatic water bath at $40 \pm 0.5{ }^{\circ} \mathrm{C}$ and maintained under controlled agitation with a magnetic stirrer $(300 \mathrm{rpm})$ for $10 \mathrm{~min}$ to reach equilibrium conditions before SPME insertion. A SPME, $75 \mu \mathrm{m}$ Carboxen ${ }^{\circledR} /$ PDMS fibre preconditioned according to manufacturer's instructions (Supelco, PA, USA) was employed. The fibre was inserted into the GC injector for analysis and kept at $260{ }^{\circ} \mathrm{C}$. The desorption time was $1 \mathrm{~min}$. The GC used in this work was an HRGC 5300 MEGA SERIES Instrument (Carlo Erba, MI, Italy) equipped with a split/splitless injector and a flame ionization detector (FID). A fused-silica SE 54 capillary column (25 m $\times 0.25 \mathrm{~mm}$ I.D., $0.25 \mu \mathrm{m}$ film thickness; MEGA s.n.c, MI, Italy) was employed. Helium (99.999\%) was used as a carrier gas at a constant head pressure of $30 \mathrm{kPa}$ and a constant flow-rate (1 $\mathrm{mL} \mathrm{min}^{-1}$ ). Hydrogen and air were used to maintain the detector flame at a pressure of 40 and $80 \mathrm{kPa}$, respectively. The detector temperature was kept constant at $250{ }^{\circ} \mathrm{C}$. The GC oven was programmed as follows: $35{ }^{\circ} \mathrm{C}(5 \mathrm{~min}), 5^{\circ} \mathrm{C} \mathrm{min}{ }^{-1}$ to $80{ }^{\circ} \mathrm{C}(5 \mathrm{~min})$, $30{ }^{\circ} \mathrm{C} \min ^{-1}$ to $150{ }^{\circ} \mathrm{C}(5 \mathrm{~min})$.

The linearity of the method for the quantitative analysis was tested by evaluating the calibration curves: standard solutions of MTBE in MilliQ ${ }^{\circledR}$ (Millipore, MA, USA) water were analysed at varying concentration levels in the $0.1-15$ and $10-300 \mathrm{mg} \mathrm{L}^{-1}$ ranges. Each concentration was analysed twice. The linearity range was evaluated, as well as the method detection limit (LOD) computed from the calibration line.

Adsorption isotherm. Adsorption isotherms were determined using the batch method on as-synthesized zeolites. Batch experiments were carried out in duplicate in $25 \mathrm{~mL}$ crimp top reaction glass flasks sealed with PTFE septa (Supelco, PA, USA). The flasks were filled in order to have the minimum headspace, a solid/solution ratio of $1: 4\left(\mathrm{mg} \mathrm{mL}^{-1}\right)$ was employed. After equilibration, $(24 \mathrm{~h})$ at a temperature of $25.3 \pm$ $0.5{ }^{\circ} \mathrm{C}$ under stirring, the solids were separated from the aqueous solution using centrifugation (10 $000 \mathrm{rpm}$ for $30 \mathrm{~min}$ ) and analysed by HS-SPME-GC as described above.
Thermal analyses. Thermogravimetric (TG) and differential thermal analysis (DTA) measurements of the exhausted and bare zeolite samples were performed in air using an STA 409 PC LUXX®-Netzch operating at $10{ }^{\circ} \mathrm{C} \mathrm{min}^{-1}$ heating rate, from room temperature (RT) to $900{ }^{\circ} \mathrm{C}$.

$\mathrm{X}$-ray powder diffraction measurements and structure determination. X-Ray powder diffraction (XRPD) patterns of zeolite ZSM-5 and Y after MTBE adsorption (Y-MTBE, and ZSM5-MTBE, respectively) were measured on a Bruker D8 Advance Diffractometer equipped with a $\mathrm{Si}(\mathrm{Li})$ solid-state detector, $(\mathrm{Cu}$ $\mathrm{K} \alpha 1,2$ radiation, $3-110^{\circ} 2 \theta$ range, counting time of $12 \mathrm{~s}$ per $0.02^{\circ}$ $2 \theta$ step). The structural refinements were run by the Rietveld method using the GSAS-EXPGUI software packages. ${ }^{28,29}$ Structural features of bare zeolites can be found in ref. 24 and 25 respectively. Full matrix least-square refinements of MTBE loaded zeolites were carried out in the $F d \overline{3}$ (for zeolite $\mathrm{Y}$ ), and $P 2_{1} / n$ (for ZSM-5) space groups, respectively. Framework and extra-framework atomic coordinates, and temperature factors are provided as ESI. $\dagger$

Infrared analysis. Infrared spectra were collected on a Thermo Electron Corporation FT Nicolet 5700 spectrometer with $4 \mathrm{~cm}^{-1}$ resolution. Before the IR analysis, ZSM-5 zeolite was calcined at $450{ }^{\circ} \mathrm{C}$ for $4 \mathrm{~h}$ to remove residual ammonium species whose presence makes uneasy the interpretation of IR signals in the high frequency range. Because of the low amount of ammonium species contained into the ZSM-5 unit cell (calculated as $\leq 0.7$ molecules according to the formula $\mathrm{Si}_{95.3^{-}}$ $\left.\mathrm{Al}_{0.7} \mathrm{O}_{190.6}\left(\mathrm{NH}_{4}^{+}\right)_{0.7}\right)$, it is expected that the treatment does not significantly affect the sorption properties of the ZSM-5 zeolite. Self-supporting pellets of zeolite ZSM-5 and Y samples were obtained with a mechanical press at ca. 3 and 2 tons $\mathrm{cm}^{-2}$, respectively, and placed into an IR cell equipped with $\mathrm{KBr}$ windows permanently attached to a vacuum line (residual pressure $\leq 1 \times 10^{-4} \mathrm{mbar}$ ), allowing thermal treatments and MTBE and/or water adsorption/desorption experiments to be carried out in situ. Spectra of MTBE and/or water adsorbed on the two zeolites were collected at beam temperature $\left(\mathrm{ca} .35^{\circ} \mathrm{C}\right)$ on samples previously dehydrated for $30 \mathrm{~min}$ under vacuum at beam temperature or after outgassing zeolite ZSM-5 and Y for 2 $\mathrm{h}$ at 700 and $500{ }^{\circ} \mathrm{C}$, respectively, in order to remove the fraction of silanols interacting each other by hydrogen bonding. Spectra of the bare zeolite under the different conditions were recorded for comparison.

\section{Results and discussion}

\subsection{Adsorption isotherms from aqueous solutions}

Fig. 2A shows MTBE adsorption isotherms on ZSM-5 and Y, obtained for dilute aqueous solutions at $25{ }^{\circ} \mathrm{C}$. The aqueous phase MTBE concentrations in the $\mu \mathrm{g} \mathrm{L}^{-1}$ range is interesting because it represents the level of concern for natural and drinking water. In Fig. 2A, it can be seen that both the isotherms follow a linear trend, and by comparing the slope of the linear equation it can also be noticed that $\mathrm{Y}$ is less efficient in MTBE removal from water solutions than ZSM-5. Additionally, a similar behaviour was observed for DCE adsorption on Y and ZSM-5. ${ }^{25}$ Similar trends have also been reported in the 

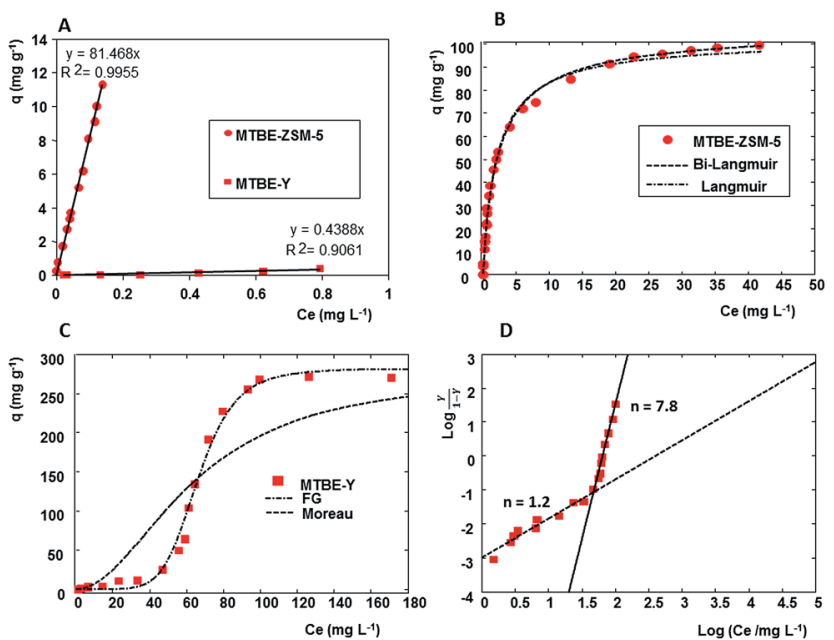

Fig. 2 (A) MTBE adsorption isotherms on ZSM-5 and $Y$ in lower concentration range, (B) MTBE adsorption isotherm on ZSM-5, (C) MTBE adsorption isotherm on $Y$ fitted with a Moreau and FowlerGuggenheim (FG) models, (D) MTBE adsorption isotherm on $Y$ fitted with a Hill model, $Y$ is the fractional loading.

literature. ${ }^{30,31}$ On the contrary, the shape of the adsorption isotherms of MTBE on ZSM-5 and Y differ from each other when a wide range of concentrations is considered, (see Fig. 2B and C). In this case the aqueous MTBE concentrations are included the $\mathrm{g} \mathrm{L}^{-1}$ range which is below the aqueous solubility (i.e. $50 \mathrm{~g}$ $\mathrm{L}^{-1}$ ) and might be encountered in the event of spill. In particular, in Fig. 2B and C, it can be seen that the adsorption data on ZSM-5 follow a type I, whereas, the $\mathrm{Y}$ data follow a type $\mathrm{V}$ isotherm according to IUPAC classification, ${ }^{32}$ and that $\mathrm{Y}$ zeolite adsorbed very effectively at higher concentrations. A similar behaviour has been already observed for the adsorption of DCE on these two zeolites. ${ }^{25}$ The type I isotherms are usually fitted by Langmuir, or heterogeneous extended Langmuir models: ${ }^{33}$

where $q_{\mathrm{s}}$ and $b$ are the monolayer saturation capacities and the equilibrium constant respectively. In this model, the interaction between molecules in neighbouring cages are considered negligible. ${ }^{34}$ The data were also fitted using a bi-Langmuir isotherm type, which take into account of the presence of two adsorption sites characterized by different interaction energies:

$$
q_{\mathrm{e}}=\frac{q_{\mathrm{s}, 1} b_{1} c_{\mathrm{e}}}{1+b_{1} c_{\mathrm{e}}}+\frac{q_{\mathrm{s}, 2} b_{2} c_{\mathrm{e}}}{1+b_{2} c_{\mathrm{e}}}
$$

where $b$ and $q_{\mathrm{s}}$ have the same meaning as in the previous equation and the subscripts refer to sites 1 and 2, respectively. Fig. 2B shows the agreement between experimental adsorption data of MTBE onto ZSM-5 and the Langmuir and bi-Langmuir adsorption isotherm models. Non linear fitting was employed to obtain the model parameters. The isotherm models are not significantly different in the low concentration range, they differ slightly solely in the high concentration range.

Table 1 lists the best adsorption isotherm parameters. To statistically compare the two model, the ratio of the Fisher

$$
q_{\mathrm{e}}=\frac{q_{\mathrm{s}} K c_{\mathrm{e}}}{1+K c_{\mathrm{e}}}
$$

parameter was calculated ${ }^{35}$ from the sum of the squares of the residuals (SSE, see Table 1). As suggested by Gritti, ${ }^{36}$ one isotherm model would be statistically better than the other one if the ratio of their two Fisher parameters would exceed 3.47, given their degrees of liberty $d_{1}$ and $d_{2}\left(d_{1}=25-4=21, d_{2}=25\right.$ $-2=23$ ) and a level of risk $\alpha$ of 0.05 . Since the Fisher parameter was 3.35, the bi-Langmuir and the Langmuir adsorption models seem to be statistically equivalent. In such a case, the adsorption data provide insufficient insight to the adsorption mechanisms and the choice between the two adsorption model should be based on the knowledge of the adsorption process.

Consequently, to gain information on the ZSM-5 adsorption sites a structural investigation was performed in order to localize the MTBE molecules in the ZSM-5 framework, the results are reported in Rietveld refinement section.

For that which concerns $\mathrm{Y}$ zeolite, on one hand, it was observed a higher saturation capacity than that of ZSM-5, probably related to the higher pore volumes of $\mathrm{Y}$ as well as to the different framework geometry, mesopores and/or framework defect density with respect to ZSM-5. ${ }^{27}$ Recently, Pasti et al. $^{25}$ demonstrated that the adsorption properties of zeolitic materials are not only affected by the SAR and the size of the micropores but also by their structural features. On the other hand, the affinity at low MTBE concentrations to Y was lower than that to ZSM-5. The difference in affinity of the two zeolites indicates that different interaction types occur between MTBE and the zeolite framework. Reasonably, the difference in the adsorption properties between Y and ZSM-5 arises from the interference of water in the adsorption process. To investigate the adsorption process of MTBE, the experimental data were fitted by using various isotherm models. Several mathematical models can be used to describe adsorption data: among them, Moreau, Hill, Fowler-Guggenheim (F-G) isotherm models are those most frequently employed to fit S-shaped isotherms. ${ }^{37,38}$

Table 1 Isotherm parameters for the adsorption of MTBE on ZSM-5 and $Y$
$R^{2}$

MTBE-ZSM-5

MTBE-ZSM-

MTBE-Y

\begin{tabular}{|c|c|c|c|}
\hline \multicolumn{4}{|c|}{ Langmuir } \\
\hline $\begin{array}{l}q_{\mathrm{s}} \\
b\end{array}$ & $\begin{array}{l}94 \\
0.498\end{array}$ & 0.9946 & 155.8 \\
\hline \multicolumn{4}{|c|}{ Bi-Langmuir } \\
\hline $\begin{array}{l}q_{\mathrm{s}, 1} \\
b_{1}\end{array}$ & $\begin{array}{l}62 \\
0.683\end{array}$ & 0.9959 & 118.1 \\
\hline $\begin{array}{l}q_{\mathrm{s}, 2} \\
b_{2} \\
\text { Mor }\end{array}$ & $\begin{array}{l}32 \\
0.234\end{array}$ & & \\
\hline $\begin{array}{l}q_{\mathrm{s}} \\
b\end{array}$ & $\begin{array}{l}364 \\
0.067\end{array}$ & 0.8926 & 4870 \\
\hline$I$ & 61.12 & & \\
\hline \multicolumn{4}{|l|}{ Hill } \\
\hline$q_{\mathrm{s}}$ & 281 & 0.9921 & 1800.3 \\
\hline$K_{\mathrm{D}}$ & 73 & & \\
\hline$N$ & 6.5 & & \\
\hline \multicolumn{4}{|c|}{ Fowler-Guggenheim } \\
\hline$K_{\mathrm{FG}}$ & 0.00153 & 0.9912 & 0.923 \\
\hline$W$ & 5.805 & & \\
\hline
\end{tabular}
SSE 
The Moreau isotherm model describe the adsorption onto an homogeneous adsorbent surface on which adsorbate-adsorbate interactions take place, ${ }^{37}$ moreover, this model is nearly identical to the Ruthven model developed for adsorption on zeolites: ${ }^{39}$

$$
q_{\mathrm{e}}=q_{\mathrm{s}} \frac{b c_{\mathrm{e}}+I b^{2} c_{\mathrm{e}}^{2}}{1+2 b c_{\mathrm{e}}+I b^{2} c_{\mathrm{e}}^{2}}
$$

where $b$ and $q_{\mathrm{s}}$ have the same meaning as in the previous equation, and $I$ is the adsorbate-adsorbate interaction parameter in the monolayer, it is related to the interaction energy, $\left(\varepsilon_{\mathrm{AA}}\right)$ between two neighbor adsorbed molecules of compound $\mathrm{A}$ by the following relationship:

$$
I=\exp \left(\varepsilon_{\mathrm{AA}} / R T\right)
$$

The Hill isotherm model is employed to describe cooperative sorption mechanism:

$$
q_{\mathrm{e}}=q_{\mathrm{s}} \frac{c_{\mathrm{e}}^{n}}{K_{\mathrm{H}}+c_{\mathrm{e}}^{n}}
$$

where $K_{\mathrm{H}}$ is Hill constant, and $n$ is the Hill coefficient which is related to the degree of cooperativity. The Hill model is generally used to evaluate the binding of substrates to biomolecules. ${ }^{40}$ However it has also be applied to investigate the adsorption properties of carbonaceous materials, zeolites and more recently soft nanoporous crystals. ${ }^{41}$

Finally, the F-G isotherm model, is the most employed equation in fitting adsorption data of organic compounds on zeolite and porous materials. ${ }^{\mathbf{4 2}}$

$$
K_{\mathrm{FG}} c_{\mathrm{e}}=\frac{\theta}{1-\theta} \exp \left(\frac{2 \theta W}{R T}\right)
$$

where $K_{\mathrm{FG}}$ is the $\mathrm{F}-\mathrm{G}$ equilibrium constant, $\theta$ the fractional coverage (equal to $q_{\mathrm{e}} / q_{\mathrm{s}}$ ), $R$ the universal gas constant, $T$ the temperature $(\mathrm{K})$, and $W$ is the interaction energy between adsorbed molecules.

In Table 1 are reported the fitting parameters obtained for the three models tested. The experimental data was fitted with the linear form of the $\mathrm{F}-\mathrm{G}$ equation, whereas non linear regression was carried out for the other two models. To evaluate the fractional coverage, in the $\mathrm{F}-\mathrm{G}$ equation, the saturation capacity was evaluated by non linear fitting of the data with a shifted Langmuir model. The determination coefficient of the Moreau isotherm model is lower than the others, thus indicating a poor fitting of the model. In order to examine the models, the fitting equations and the experimental isotherm were plotted (see Fig. 2C). The variables in the $\mathrm{F}-\mathrm{G}$ equation cannot be separated and, in this case, a simulated isotherm was calculated for each equilibrium concentration using a computer code. It can be noticed in Fig. $2 \mathrm{C}$ that both the F-G and the Hill model well describe the equilibrium isotherms. The interaction energy estimated from $\mathrm{F}-\mathrm{G}$ model is positive thus indicating interaction of the adsorbate molecules.

Additionally the Hill plot of the data was calculated (see Fig. 2D) and the shape of the plot indicated a cooperative mechanism in the adsorption process $(n=7.8)$. Therefore both the models evidenced strong adsorbate-adsorbate interactions. To gain insight into the MTBE-Y system, a structural and spectroscopic investigation was carried out. Finally, by comparing the data of MTBE-Y system to those of the DCE-Y ${ }^{25}$ it seems that $\mathrm{Y}$ zeolite is selective for the least water-soluble compound. This finding has been observed also for the adsorption of VOCs in gas/solid adsorption. ${ }^{43}$

\subsection{Rietveld refinement}

ZSM-5-MTBE. After MTBE adsorption, the ZSM-5-MTBE diffraction peak positions are quite similar to those reported for the untreated materials (see Fig. S1 in the ESI $\dagger$ ) and consequently, unit-cell parameters are not remarkably modified (Fig. 1A). In the low $2 \theta$ region the peak intensities (see Fig. S1 ESI $\dagger$ ), which are strongly dependent on the arrangement and occupancy of species in the zeolite cavities, are markedly different in the two patterns suggesting the MTBE molecules entering in the ZSM-5 channels. After adsorption, the apertures became more elliptical and larger than the bare zeolite (see Fig. 1A). Specifically, Crystallographic Free Area values from ZZ ring $\mathrm{A}, \mathrm{ZZ}$ ring $\mathrm{B}$, SC ring $\mathrm{A}$ and $\mathrm{SC}$ ring $\mathrm{B}$ increased and the overall effect of these variations accounts for the slight cell volume contraction observed with respect to the as-synthesized material (see Fig. 1A).

Two crystallographically independent MTBE sites were localized: the first one (MTBE1 in Fig. 3A is located near the intersections of sinusoidal and straight 10MR channels (C1a, C2a, C3a, C4a, C5a, O1a sites in Table S1 ESI $\dagger$ ) and the second one (MTBE2 in Fig. 3A) in the sinusoidal 10MR channel (C1b, C2b, C3b, C4b, C5b, O1b sites in Table S1 ESI†), respectively.

The occupancy factors indicate that the level of loading is 8 MTBE molecules per unit cell, Fig. 3A shows the high-loaded structure of ZSM-5-MTBE, with the guest molecules located in both channels, in common with other non-aromatic hydrocarbons. ${ }^{44-46}$ Although ZSM-5 is hydrophobic, difference Fourier maps revealed the presence of a further extra-framework site partially occupied by a low amount of water molecules (W site in Table S2 ESI $\dagger$ ). On the whole, 8 MTBE molecules (corresponding to $\sim 11 \%$ zeolite dry weight $(\mathrm{dw})$ ) and about 2 water molecules (corresponding to about $0.5 \%$ zeolite $\mathrm{dw}$ ) were detected. These species are related to the weight loss occurring in the 100-900 ${ }^{\circ} \mathrm{C}$ range of the thermal analysis (green line in Fig. $4 \mathrm{~A}$ ). As reported in the TG curves of Fig. 4A, the weight loss occurring below $\sim 100{ }^{\circ} \mathrm{C}$ can be ascribed to the elimination of species weakly bonded to the surface $(\sim 5 \%$ zeolite $\mathrm{dw})$. Above this temperature, the sudden slope change (see Fig. 4B) can be reasonably due to the release/decomposition of extra-framework species (MTBE and water molecules) trapped within the MFI pores (weight loss $\sim 11.5 \% \mathrm{dw}$ ). Total weight loss at $900{ }^{\circ} \mathrm{C}$ is $16.5 \%$ for ZSM-5-MTBE, in very good agreement with the refined occupancies as well as the adsorption data. In the same temperature range, the weight loss of the as-synthesized material is equal to $5.4 \%$ and can be ascribed to the condensation of nest silanol groups.

The refined distances between the framework oxygen, water oxygen atoms and MTBE molecules suggested the occurrence of 
A

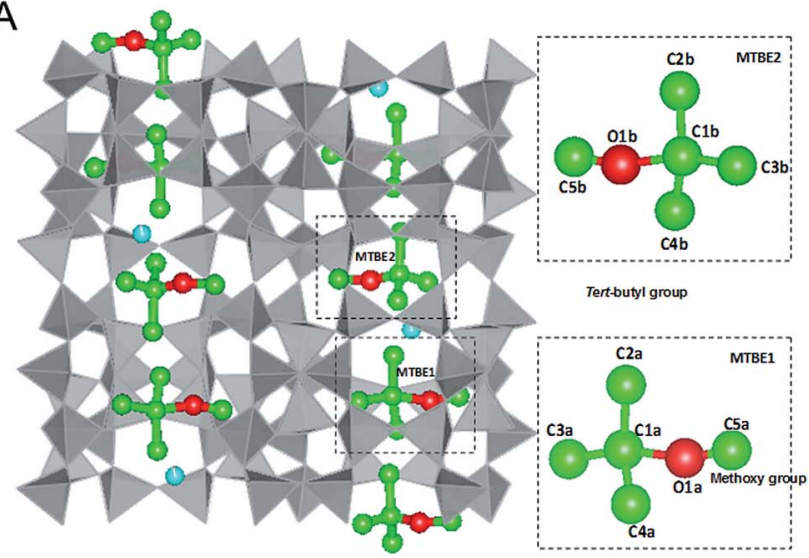

B

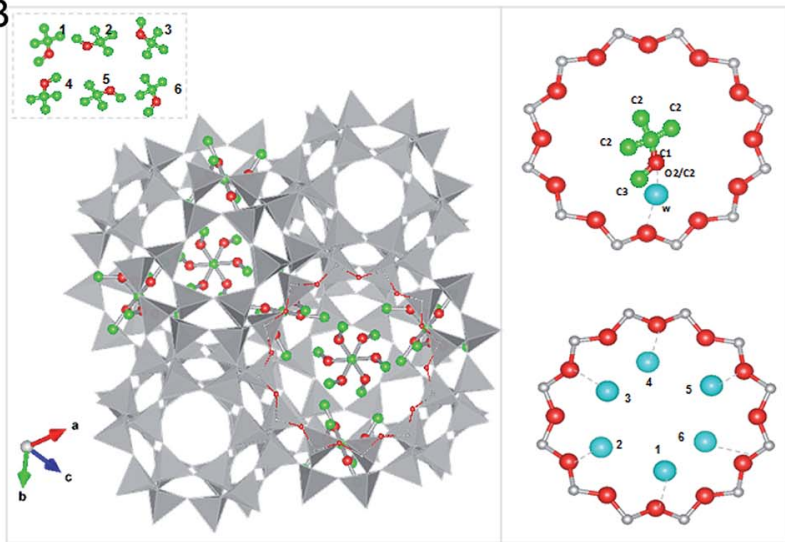

Fig. 3 Location of MTBE and water (light blue sphere) molecules in ZSM-5 (A) and in Y zeolite (B). The six possible orientations of both MTBE and water molecules are drawn in the inset for sake of clarity.

MTBE-water complexes interacting with the framework (Fig. 3A). In particular, $\mathrm{W}$ site can interact with three $\mathrm{O}$ framework oxygens as well as with MTBE molecules in both MTBE1 and MTBE2 sites $(\mathrm{W}-\mathrm{O} 25=2.61 \AA, \mathrm{W}-\mathrm{O} 31=2.97 \AA$, $\mathrm{W}-\mathrm{O} 44=$ $2.58 \AA, \mathrm{W}-\mathrm{C} 2 \mathrm{~b}=3.08 \AA, \mathrm{W}-\mathrm{C} 2 \mathrm{~b}=2.95 \AA, \mathrm{W}-\mathrm{C} 3 \mathrm{~b}=2.95 \AA$ ), thus acting as a bridge between MTBE and the framework. The refined distances of the MTBE oxygen atom from the framework oxygen atoms $(\mathrm{O} 5 \mathrm{a}-\mathrm{O} 20=2.63 \AA, \mathrm{O} 5 \mathrm{a}-\mathrm{O} 24=3.28 \AA$, O5a-O29 $=3.34 \AA$ ) suggest that MTBE molecules could interact with the framework. The importance of these interactions in stabilizing the guest structure within the zeolite host framework might therefore need reconsideration. The presence of organic compound-water molecule complexes (clusters or short chains) strongly interacting with the framework has also been recently observed in HS mordenite, ${ }^{24,25}$ ferrierite $^{18}$ as well as in the same $\mathrm{Y}$ and ZSM-5 zeolite after DCE adsorption from aqueous solutions.

Y-MTBE. Also in this case, the effective incorporation of MTBE is highlighted by a strong decrease in intensities of XRPD peaks, especially at low $2 \theta$ angles, (Fig. S2 in the ESI†). According to adsorption data, Rietveld refinement confirmed the highly relevant level of incorporation of MTBE molecules in the $\mathrm{Y}$ zeolite. The structural refinement (Fig. 1B and 3B) revealed the presence of about 32 MTBE molecules per unit cell,
A

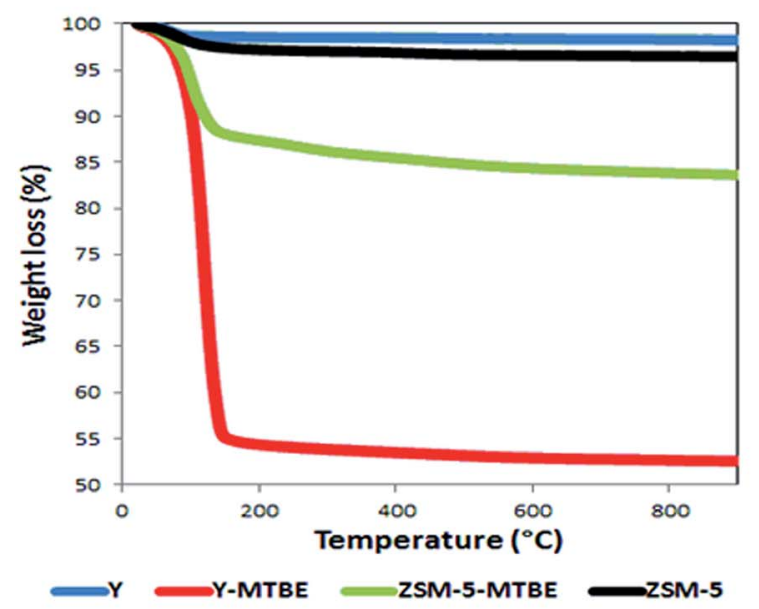

B

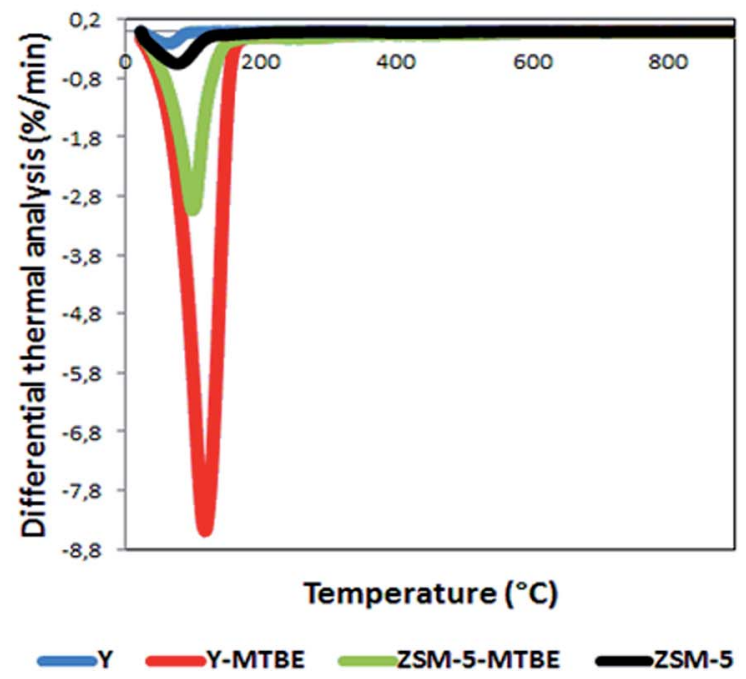

Fig. 4 (A) Thermogravimetry in dry air atmosphere of MTBE adsorbed into ZSM-5 and Y zeolites. The TG curves of untreated materials were also reported for comparison. (B) Differential thermogravimetry analysis of curves in (A).

which are located in partially occupied crystallographic sites (C1, C2 and C3 sites in Table S2 ESI †). The sorbed molecules are centred in the supercages and each shows, on a statistical basis, six possible orientations. Only one of these six positions can be occupied at any one time, due to the short distance of neighbouring MTBE molecules. The $\mathrm{C} 2$ site can be alternatively occupied by carbon or oxygen atoms $(\mathrm{O} 2 / \mathrm{C} 2)$ as the molecule symmetry is lower than $F d \overline{3}$ (Fig. 1B). The tert-butyl group is given by $\mathrm{C} 1$ and $\mathrm{O} 2 / \mathrm{C} 2$ respectively, and the methoxylic group formed $\mathrm{O} 2 / \mathrm{C} 2$ and $\mathrm{C} 3$ sites, respectively.

A further extra-framework site obtained from Difference Fourier Maps was attributed to water molecules (W site in Fig. 3B). As already observed for MTBE, water molecules can assume six different orientations, one for each MTBE positions (Fig. 3B), thus indicating a cooperative mechanism in the 
adsorption. The refined distances of the oxygen atom in the water molecules from themselves $(2.96 \AA)$ and from the O1 framework oxygen (3.16 $\AA$ ) suggest that water molecules are connected to each other to form $\mathrm{W}-\mathrm{W}$ water chains $(\mathrm{C} 2-\mathrm{W}=$ $3.10 \AA, \mathrm{C} 3-\mathrm{W}=2.38 \AA, 2.54 \AA$, and $3.05 \AA$ ). After MTBE and water adsorption, changes in the unit cell volume, as well as crystallographic free area and ellipticity of the $12 \mathrm{MR}$ channel (Fig. 1B) with respect to the as-synthesized material are highlighted. On the whole, the extra-framework content corresponds to about 11 water $(\sim 6 \%$ zeolite $\mathrm{dw})$ and $32 \mathrm{MTBE}$ molecules (corresponding to $\sim 31 \%$ zeolite $\mathrm{dw}$ ) per unit cell. These species are related to the weight loss occurring in the $100-900{ }^{\circ} \mathrm{C}$ range of the thermal analysis $(\sim 39 \%$ zeolite dw, Fig. $4 \mathrm{~A})$, in good agreement with the adsorption data.

\subsection{Infrared spectroscopy: $\mathrm{MTBE}-\mathrm{H}_{2} \mathrm{O}$ adsorption from gas phase}

According to the results on adsorption trials conducted in water, the MTBE retention by both HS zeolites is achieved through the involvement of water molecules that eventually stabilize MTBE in adsorbed form through the formation of MTBE- $\mathrm{H}_{2} \mathrm{O}$ clusters at interaction distances with the zeolite framework. In this section, the effect of water on MTBE adsorption via gas phase was investigated through IR analysis of $\mathrm{MTBE} / \mathrm{H}_{2} \mathrm{O}$ equimolar mixture. The adsorption of each single component was also reported for comparison, as well as the features of the two bare zeolites.

ZSM-5-MTBE- $\mathbf{H}_{2}$ O. Fig. 5A shows the IR spectrum of bare ZSM-5 outgassed at RT. Only the $3800-2200 \mathrm{~cm}^{-1}$ region is shown, being the part informative of the perturbation of the zeolite silanol groups (i.e. polar domain) by interactions with both water and MTBE molecules. Here, the band at ca. 3740 $\mathrm{cm}^{-1}$ can be assigned to the stretching of isolated silanols which can be both internal and external to the channels. ${ }^{16}$ The broad signal extending in the range of $c a .3750-3100 \mathrm{~cm}^{-1}$ is due to stretching modes of $\mathrm{H}$-bonded silanols mainly belonging to silanol nests. ${ }^{27}$ The two broad bands with low intensity, visible in the ranges of $c a$. 3000-2700 and $2700-2250 \mathrm{~cm}^{-1}$ and centered at $c a .2880$ and $2500 \mathrm{~cm}^{-1}$, were assigned to the stretching of bridging $\mathrm{OH}$ groups $\mathrm{H}$-bonded to water molecules $\left(\mathrm{H}_{2} \mathrm{O} \cdot \mathrm{HOZ}, \mathrm{Z}=\right.$ zeolite framework $),{ }^{47,48}$ whose occurrence was expected owing to Brønsted acid sites ( $\mathrm{Si}-\mathrm{OH}-\mathrm{Al}$ or $\mathrm{HOZ}$ ) present in the ZSM-5 zeolite $\left(\mathrm{SiO}_{2} / \mathrm{Al}_{2} \mathrm{O}_{3}=280\right)$. This suggests that a residual amount of water is still adsorbed on the sample after outgassing at RT. In the spectrum of bare ZSM-5 treated at $500{ }^{\circ} \mathrm{C}$ (Fig. 5B), where the condensation of the silanol nests reduced the corresponding stretching signal, two additional bands at 3703 and $3612 \mathrm{~cm}^{-1}$ were revealed and assigned to stretching modes of $\mathrm{H}_{2} \mathrm{O} \cdot \mathrm{HOZ}$ complex and Brønsted acid species ( $\mathrm{Si}-\mathrm{OH}-\mathrm{Al})$, respectively. ${ }^{49}$ The disappearance of the band of the acidic protons and the simultaneous increase of the signal at $3703 \mathrm{~cm}^{-1}$ is clearly evidenced in the figure.

When ZSM-5 treated at RT was contacted with 8 mbar of water (Fig. 5A), the bands of isolated silanols disappeared and a complex signal dominated by three new main maxima at $c a$. 3650,3420 , and $3240 \mathrm{~cm}^{-1}$ became visible in the region of $\mathrm{H}$ -
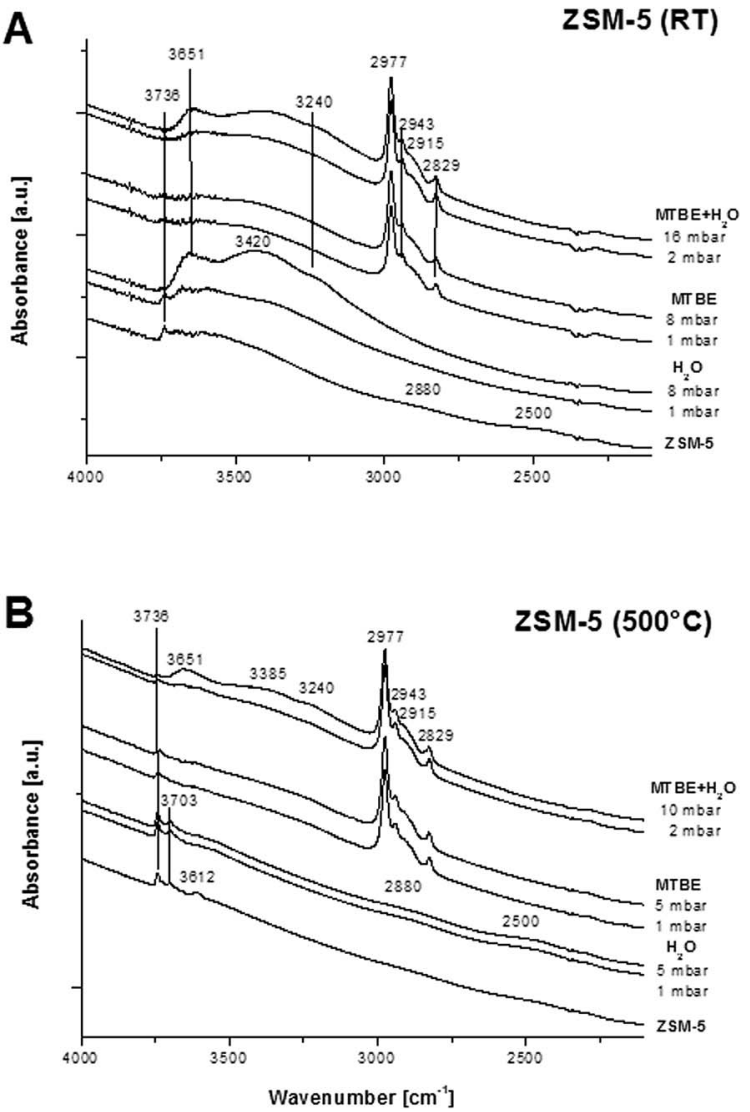

Fig. 5 Infrared spectra of ZSM-5 outgassed at (A) RT and at (B) $500{ }^{\circ} \mathrm{C}$ after adsorption of different dosage of MTBE and $\mathrm{H}_{2} \mathrm{O}$ as single components or equimolar mixture. Spectra of bare zeolite at RT and after thermal treatment are reported for comparison.

bonded $\mathrm{OH}$ stretching, thus indicating the presence of water molecules differently $\mathrm{H}$-bonded to the zeolite silanols. Since the three signals were not significantly revealed when water was contacted with ZSM-5 treated at $500{ }^{\circ} \mathrm{C}$ (Fig. 5B), it was deduced that nest silanols, and only to a minor extent, isolated silanols are involved in the water adsorption process by the zeolite. Unfortunately, the position of the bending mode of water $\mathrm{OH}$ groups was not clearly detectable because overlapped to a band at ca. $1650 \mathrm{~cm}^{-1}$, an overtone of the zeolite framework vibration. In addition, the region of $\mathrm{OH}$ stretchings shows new components in the $3740-3000 \mathrm{~cm}^{-1}$ region with respect to the bare zeolite, thus indicating $\mathrm{H}$-bonding/polar interactions between MTBE and ZSM-5 silanols.

Adsorbed MTBE shows a complex signal formed by four main bands at 2977, 2943, 2915, and $2829 \mathrm{~cm}^{-1}$, which have been already assigned to stretching modes of the two different methyl groups of methoxyl and tert-butyl moieties. ${ }^{16,27}$ In the cited studies, a detailed description of the type and strength of the host-guest interactions between MTBE and polar (silanols) or nonpolar (siloxane framework) domains in HS zeolites can be found, as well as a description of the guest-guest interactions. In our study, when ZSM-5 was contacted with a equimolar mixture of MTBE and water (16 mbar, Fig. 5A), the spectral features of both components could be found, thus indicating 
their simultaneous adsorption on ZSM-5, which is seemingly able to retain a similar amount of MTBE both in the absence and in the presence of water. Here, a few considerations can be withdrawn: the intensity and the positions of both MTBE and water bands are similar to what it was observed when they were singly adsorbed. In addition, when the loaded MTBE-water mixture was desorbed at 2 mbar, the water signals were significantly reduced whereas those of MTBE were almost completely preserved, thus indicating that water can be released more easily than MTBE molecules.

Due to the complexity of the spectral signals in the $\mathrm{OH}$ stretching region $\left(3750-3000 \mathrm{~cm}^{-1}\right)$, which are informative of possible host-guest interactions with the zeolite outgassed at $\mathrm{RT}$, no clear information on possible MTBE- $\mathrm{H}_{2} \mathrm{O}$ clusters inside the pores was obtained. A better observation of the region was achieved on ZSM-5 previously treated at $500{ }^{\circ} \mathrm{C}$.

Fig. 5B shows the adsorption of $10 \mathrm{mbar}$ of the equimolar mixture. Interestingly, here the complex signal in the $\mathrm{OH}$ stretching region shows maxima at $c a$. 3650, 3420, and 3240 $\mathrm{cm}^{-1}$ which are not visible in the zeolite singly loaded with water or MTBE, thus revealing the occurrence of H-bonded MTBE-water clusters. Also in this case, the adsorption of water is highly reversible, conversely to MTBE that remains entrapped when the pressure was reduced to 2 mbar.

These findings are in agreement to what it was obtained by the Rietveld analysis of XRPD data of the zeolite loaded with MTBE from water solution where water molecules are found stabilized by interactions with MTBE and the zeolite framework. Likely, the extra-stabilization of van der Waals forces acting on the organic component of H-bonded MTBE-water cluster, forces water to stay at interaction distance to the zeolite framework.

Y-MTBE- $\mathbf{H}_{2} \mathbf{O}$. IR spectrum of the bare zeolite $\mathrm{Y}$ outgassed at RT is shown in Fig. 6A. Only the $4000-1350 \mathrm{~cm}^{-1}$ region is shown because it is informative of the perturbation of the zeolite polar domains by both water and MTBE. Here, the band at $3737 \mathrm{~cm}^{-1}$ and the broad signal centered at $c a .3535 \mathrm{~cm}^{-1}$ are stretching modes of isolated and nest $\mathrm{H}$-bonded silanols, respectively.

After interaction with pure water (8 mbar), a partial reduction of the band at $3737 \mathrm{~cm}^{-1}$ was observed, thus indicating a uncomplete reactivity/accessibility of isolated silanols to water molecules. In addition, a new component centered at $c a .3430$ $\mathrm{cm}^{-1}$, assigned to stretching modes of $\mathrm{H}$-bonded $\mathrm{OH}$ groups belonging to both the zeolite and water, could be observed. At lower frequencies, the bending mode of water $\mathrm{OH}$ groups at $c a$. $1630 \mathrm{~cm}^{-1}$ could be also found. When MTBE (8 mbar) was singly adsorbed on the zeolite $\mathrm{Y}$, a new complex band at $c a .3290$ $\mathrm{cm}^{-1}$ became visible beside the occurrence of MTBE bands between 3000 and $2800 \mathrm{~cm}^{-1}$, thus indicating the interaction of silanol groups with MTBE molecules. A detailed description of the polar and nonpolar host-guest interactions between MTBE and the zeolite $\mathrm{Y}$ has been already given elsewhere. ${ }^{27}$ When the zeolite was exposed to a equimolar MTBE- $\mathrm{H}_{2} \mathrm{O}$ mixture $(16$ mbar), beside the occurrence of MTBE bands, the $\mathrm{OH}$ stretching and bending regions resembled the spectral features of both components, thus revealing their co-adsorption. Interestingly,
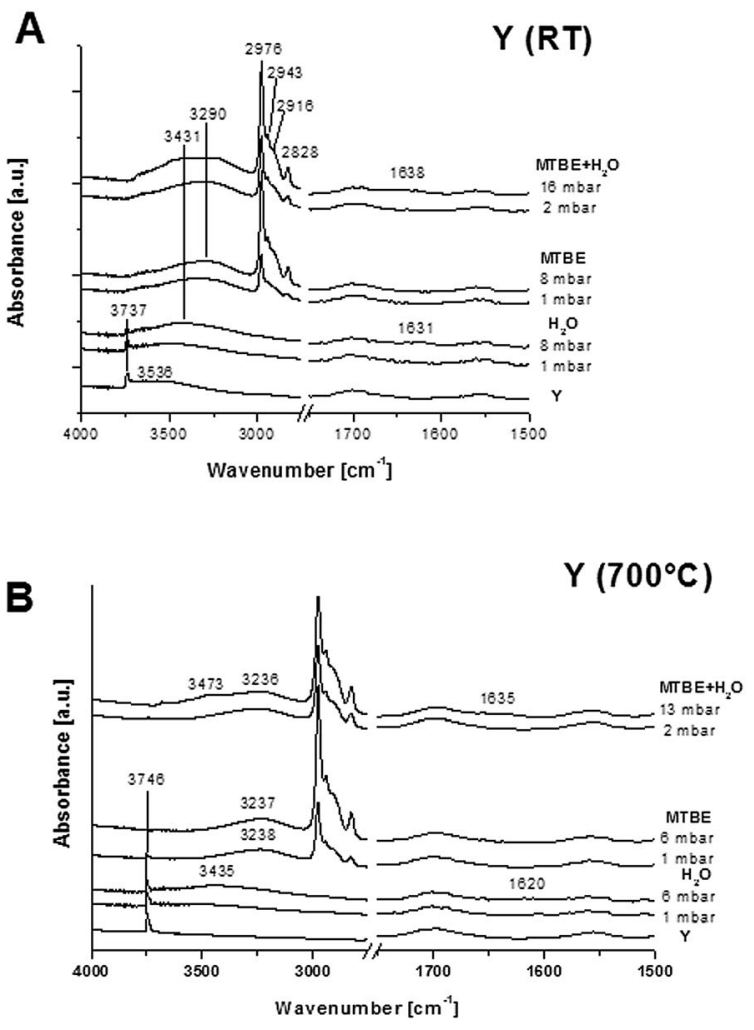

Fig. 6 Infrared spectra of zeolite $Y$ outgassed at (A) RT and at (B) $700{ }^{\circ} \mathrm{C}$ after adsorption of different dosage of MTBE and $\mathrm{H}_{2} \mathrm{O}$ as single components or equimolar mixture. Spectra of bare zeolite at RT and after thermal treatment are reported for comparison.

the water $\mathrm{OH}$ bending at $1638 \mathrm{~cm}^{-1}$ is found slightly upshifted $\left(+7 \mathrm{~cm}^{-1}\right)$ with respect to the same signal of singly adsorbed water at $1631 \mathrm{~cm}^{-1}$. This indicates that co-adsorbed MTBE molecules affect the chemical surrounding of water molecules. According to the $\mathrm{H}$-bonding theory ${ }^{48}$ the blue shift of the $\mathrm{OH}$ bending is associated to a ten/sevenfold redshift of the stretching signal of the related $\mathrm{OH}$ groups.

Unfortunately, the complexity of this region in our spectrum did not allow to clearly define the stretching component associated to the $\mathrm{OH}$ of water molecules $\mathrm{H}$-bonded to MTBE. However, when the zeolite loaded with the mixture was outgassed to 2 mbar, both the signal at $1638 \mathrm{~cm}^{-1}$ and the component at $3431 \mathrm{~cm}^{-1}$ simultaneously disappeared, being thus referred to the same $\mathrm{H}$-bonded water species.

Similar features were found in the IR spectrum of the mixture $(13 \mathrm{mbar})$ contacted with the zeolite previously outgassed at $700{ }^{\circ} \mathrm{C}$ (Fig. 6B). Here, the nested silanols possibly interacting with MTBE or $\mathrm{H}_{2} \mathrm{O}$ were removed by condensation, and the band at $1635 \mathrm{~cm}^{-1}$, assigned to the bending mode of water $\mathrm{OH}$ groups, was shifted of $+15 \mathrm{~cm}^{-1}$ with respect to the same signal $\left(1620 \mathrm{~cm}^{-1}\right)$ of singly adsorbed water $(6 \mathrm{mbar})$. Finally, as far as the stability of the mixture components retained inside the $\mathrm{Y}$ porosities, when the zeolite loaded with the equimolar MTBE/water mixture (Fig. 6A) was outgassed to 2 mbar, water was easily desorbed by the HS zeolite whereas MTBE was partially retained. 


\section{Conclusions}

The adsorption of MTBE onto HS MFI and FAU zeolites was investigated under different conditions: by batch adsorption and X-ray powder diffraction analyses from aqueous solution, and by infrared spectroscopy from gas phase in the presence of water. MTBE exhibits a type-I isotherm on MFI and a type-V isotherm on FAU, thus indicating a different interaction mechanism. In particular, the adsorption of MTBE on Y seems to be cooperative, thus involving adsorbate-adsorbate interactions. The adsorption Henry's constants for MTBE decreases with an increase in the zeolite pore size, indicating that confinement of the adsorbate in the zeolite pores is a driving force for adsorption. On the contrary, the saturation capacity increases with an increase in the adsorbent pore size (i.e. about 95 and $250 \mathrm{mg} \mathrm{g}^{-1}$ for ZSM-5 and Y, respectively). These data were confirmed from Rietveld refinement, that clearly revealed the incorporation of about 8 and 32 MTBE molecules per ZSM-5 and $\mathrm{Y}$ unit cell respectively. X-ray diffraction and IR spectroscopy indicate that significant clustering of the guest molecules (i.e. water and MTBE) occurs in the two investigated zeolites during adsorption from both liquid and gas phase. The clusters originate from H-bonding between MTBE and water molecules and their interaction with zeolite leads to framework flexibility for both zeolites. Water plays an important role in the adsorption process of MTBE from gas phase as well, with no significant reduction of retention capacity for both zeolites. These findings can be of a certain interest for scientists working with PRB technologies as well as with the decontamination of wet indoor environments from oxygenated organic compounds.

\section{Acknowledgements}

The authors thank the Research Centre for Unconventional Energies, Istituto ENI G. Donegani - Environmental Technologies (San Donato Milanese (MI) Italy) for financial support.

\section{Notes and references}

1 J. Fenger, Atmos. Environ., 2009, 43, 13.

2 OEHHA (Office of Environmental Health Hazard Assessment), 1999 in Drinking Water, Pesticide and Environmental Toxicology Section, California EPA, USA, http://oehha.ca.gov/water/phg/pdf/mtbe_f.pdf.

3 A. Amberg, E. Rosner and W. Dekant, Toxicol. Sci., 2001, 61, 62.

4 D. Mackay, W. Y. Shiu, K. C. Ma and S. C. Lee, Illustrated handbook of physical-chemical properties and environmental fate for organic chemicals-volatile organic chemicals, Taylor \& Francis Group, LLC., 2006, vol. III, pp. 1-925.

5 P. Squillace, J. Pankow, N. Kortes and J. Zogorski, Environ. Toxicol. Chem., 2009, 16(9), 1836.

6 US EPA in Washington, DC, US Environmental Protection Agency, 1997, pp. 11-13 (EPA-822-F-97-009), http:// www.epa.gov/ost/drinking/mtbe.pdf.

7 P. Chang and T. Young, Water Res., 2000, 34, 2233.
8 J. L. Graham, R. Striebich, C. L. Patterson, E. Radha Krishnan and R. C. Haught, Chemosphere, 2004, 54, 1011.

9 N. B. Milestone and D. M. Bibby, J. Chem. Technol. Biotechnol., 1981, 31(1), 732.

10 R. W. Grose and E. M. Flanigen, Patent US 4257885 A, 1981. 11 A. O. Yazaydin and R. W. Thompson, J. Phys. Chem. B, 2006, 110, 14458.

12 L. Abu-Laila, J. A. Bergendahl and R. W. Thompson, J. Hazard. Mater., 2010, 1-3, 363.

13 M. A. Anderson, Environ. Sci. Technol., 2000, 34, 725.

14 A. Rossner and D. R. Knappe, Water Res., 2008, 42, 2287.

15 L. Shiguang, V. A. Tuan, R. D. Noble and J. L. Falconer, Environ. Sci. Technol., 2003, 37, 4007.

16 V. Sacchetto, G. Gatti, G. Paul, I. Braschi, G. Berlier, M. Cossi, L. Marchese, R. Bagatin and C. Bisio, Phys. Chem. Chem. Phys., 2013, 15, 13275.

17 R. Arletti, A. Martucci, A. Alberti, L. Pasti, M. Nassi and R. Bagatin, J. Solid State Chem., 2012, 194, 135.

18 A. Martucci, L. Leardini, M. Nassi, E. Sarti, R. Bagatin and L. Pasti, Mineral. Mag., 2014, 78, 1161.

19 M. Thommes, Studies in Surface Science and Catalysis, 3rd revised version, ed. J. Cejka, H. van Bekkum, A. Corma and F. Schüth, 2007, vol. 168, p. 495.

20 P. Bai, M. Tsapatsis and J. I. Siepmann, Langmuir, 2012, 28(44), 15566.

21 R. Krishna and J. M. van Baten, Langmuir, 2010, 26, 10854.

22 E. E. Mallon, M. Y. Jeon, M. Navarro, A. Bhan and M. Tsapatsis, Langmuir, 2013, 29(22), 6546.

23 J. I. Siepmann and A. E. Clark, J. Phys. Chem. C, 2014, 118(34), 19723.

24 A. Martucci, L. Pasti, M. Nassi, A. Alberti, R. Arletti, R. Bagatin, R. Vignola and R. Sticca, Microporous Mesoporous Mater., 2012, 151, 358-367.

25 L. Pasti, A. Martucci, M. Nassi, A. Cavazzini, A. Alberti and R. Bagatin, Microporous Mesoporous Mater., 2012, 160, 182.

26 C. Baerlocher, W. M. Meier and D. H. Olson, Atlas of Zeolite Framework Types, Elsevier, Amsterdam, 5th edn, 2001.

27 I. Braschi, G. Gatti, C. Bisio, G. Berlier, V. Sacchetto, M. Cossi and L. Marchese, J. Phys. Chem. C, 2012, 116, 6943.

28 A. C. Larson and R. B. Von Dreele, General Structure Analysis System (GSAS), Los Alamos National Laboratory Report LAUR, 2000, p. 86.

29 B. H. Toby, J. Appl. Crystallogr., 2001, 34, 210.

30 J. Farrell, C. Manspeaker and J. Luo, Microporous Mesoporous Mater., 2003, 59, 205.

31 S. Kleineidam, C. Schüth and P. Grathwohl, Environ. Sci. Technol., 2002, 36, 4689.

32 K. S. W. Sing, Pure Appl. Chem., 1985, 57(4), 603-619.

33 B. A. de Moor, M.-F. Reyniers, O. C. Gobin, J. A. Lercher and G. B. Marin, J. Phys. Chem. C, 2011, 115, 1204.

34 D. G. Ruthven, Principles of adsorption and adsorption processes, Wiley-Interscience; John Wiley \& Sons, N.Y. (USA), 1984.

35 D. L. Massart, B. G. M. Vandengiste, S. N. Deming, Y. Michotte and L. Kaufman, Chemometrics: A Textbook, Elsevier, Amsterdam, 2nd edn, 1988. 
36 F. Gritti, W. Piatkowskia and G. Guiochon, J. Chromatogr. A, 2002, 978(1-2), 81.

37 F. Gritti and G. Guiochon, Anal. Chem., 2004, 76, 4779.

38 K. Y. Foo and B. H. Hameed, Chem. Eng. J., 2010, 156, 2.

39 D. G. Ruthven, Principles of adsorption and adsorption processes, Wiley-Interscience; John Wiley \& Sons, N.Y. (USA), 1984.

40 S. Goutellea, M. Maurinc, F. Rougierb, X. Barbautb, L. Bourguignon, M. Ducherb and P. Maire, Fundam. Clin. Pharmacol., 2008, 22, 633.

41 H. Sato, W. Kosaka, R. Matsuda, A. Hori, Y. Hijikata, R. V. Belosludov, S. Sakaki, M. Takata and S. Kitagawa, Science, 2014, 343, 167.

42 O. Hamdaouia and E. Naffrechoux, J. Hazard. Mater., 2007, 147, 381.
43 Y. J. Ho, D. K. Choi and S. H. Kim, Adsorption of organic solvent vapors on hydrophobic Y-type zeolite, AIChE J., 1998, 44, 1344.

44 S. Fujiyama, N. Kamiya, K. Nishi and Y. Yokomori, Acta Crystallogr., Sect. B: Struct. Sci., Cryst. Eng. Mater., 2014, 70, 856.

45 S. Fujiyama, S. Seino, N. Kamiya, K. Nishi, K. Yoza and Y. Yokomori, Phys. Chem. Chem. Phys., 2014, 16, 15839.

46 J. O. Titiloye, S. C. Parker, F. S. Stone and C. R. A. Catlow, J. Phys. Chem., 1991, 95, 4038.

47 L. Smith, A. K. Cheetham, R. E. Morris, L. Marchese, J. M. Thomas, P. A. Wright and J. Chen, Science, 1996, 271, 799.

48 S. Coluccia, L. Marchese and G. Martra, Microporous Mesoporous Mater., 1999, 30, 43.

49 A. Novak, Struct. Bonding, 1974, 18, 177. 